\title{
Proteomics analysis reveals heat shock proteins involved in caprine parainfluenza virus type 3 infection
}

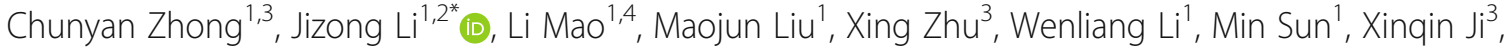
Fang Xiao ${ }^{1,3}$, Leilei Yang ${ }^{1}$, Wenwen Zhang $^{1}$ and Zheng Liao ${ }^{1,3}$

\begin{abstract}
Background: Caprine parainfluenza virus type 3 (CPIV3) is major pathogen of goat herds causing serious respiratory tract disease and economic losses to the goat industry in China. We analyzed the differential proteomics of CPIV3infected Madin-Darby bovine kidney (MDBK) cells using quantitative iTRAQ coupled LC-MS/MS. In addition, four DEPs were validated by qRT-PCR and western blot analysis.

Results: Quantitative proteomics analysis revealed 163 differentially expressed proteins (DEPs) between CPIV3-infected and mock-infected groups ( $p$-value $<0.05$ and fold change $>1.2$ ), among which 91 were down-regulated and 72 were up-regulated. Gene ontology (GO) analysis showed that these DEPs were involved in molecular functions, cellular components and biological processes. Biological functions in which the DEPs were involved in included diseases, genetic information processing, metabolism, environmental information processing, cellular processes, and organismal systems. STRING analysis revealed that four heat shock proteins (HSPs) included HSPA5, HSPA1B, HSP90B1 and HSPA6 may be associated with proliferation of CPIV3 in MDBK cells. QRT-PCR and western blot analysis showed that the selected HSPs were identical to the quantitative proteomics data.
\end{abstract}

Conclusion: To our knowledge, this is the first report of the proteomic changes in MDBK cells after CPIV3 infection.

Keywords: Caprine parainfluenza virus type 3, Madin-Darby bovine kidney cells, Proteomic analysis, iTRAQ, LC-MS/MS

\section{Background}

In August 2013, an outbreak of severe goat respiratory disease occurred throughout the major goat herd regions of eastern China. The causative agent was identified as a novel strain of parainfluenza virus type 3 (PIV3) and was designated as caprine parainfluenza virus type 3 (CPIV3) strain JS2013 [1]. The infected goats exhibited high fever, coughing, nasal discharge and dyspnea. Necropsy of the infected goats showed mild to moderate gross lesions in the lungs, and increased amounts of secretion in the tracheas and bronchia were also observed. Genome sequence alignment and phylogenetic analysis revealed that the genome of CPIV3 strain JS2013 showed only

\footnotetext{
* Correspondence: lijizong22@sina.com

${ }^{1}$ Institute of Veterinary Medicine, Jiangsu Academy of Agricultural Sciences, Key Laboratory of Veterinary Biological Engineering and Technology, Ministry of Agriculture, Nanjing 210014, China

${ }^{2}$ School of Pharmacy, Linyi University, Linyi 276000, China

Full list of author information is available at the end of the article
}

73.3-75.5\% identity with BPIV3 and HPIV3 strains [2]. Based on phylogenetic analysis, this pathogen was designated as CPIV3, a member of the PIV3 group belonging to the Respirovirus genus within the Paramyxiviridae family. Moreover, we further demonstrated that CPIV3 strain JS2013 can be transferred horizontally between adjacent pens [3]. Recently, a seroprevalence study using 2919 serum samples in China reported a CPIV3 prevalence of $39.9 \%$ in goats [4]. Another study reported that $35 \%$ of nasal swabs and serum samples from clinically diseased goats were positive for CPIV3 by quantitative RT-PCR (qRT-PCR) [5]. It is noteworthy that the spread of CPIV3 has caused heavy economic losses in China [6].

To understand the pathogenesis of viral infection, research on virus-host interaction is critical. Virus infection can dramatically affect host cell morphology, transcription and translation patterns, the cytoskeleton, the cell cycle and innate immune responses of the host, the apoptosis

(c) The Author(s). 2019 Open Access This article is distributed under the terms of the Creative Commons Attribution 4.0 International License (http://creativecommons.org/licenses/by/4.0/), which permits unrestricted use, distribution, and reproduction in any medium, provided you give appropriate credit to the original author(s) and the source, provide a link to the Creative Commons license, and indicate if changes were made. The Creative Commons Public Domain Dedication waiver (http://creativecommons.org/publicdomain/zero/1.0/) applies to the data made available in this article, unless otherwise stated. 
pathway, and may also cause inflammation and alter stress responses [7]. Many functional and morphological changes in host cells are associated with significant changes in the patterns of expression of host cells. Therefore, information on proteome changes in the host following CPIV3 infection may be crucial to understand the host response to viral pathogenesis. In recent years, comparative proteomic analysis has emerged as a valuable tool for the establishment of the global host protein profiles in response to virus infection [8]. This technique has been widely used to investigate proteome changes in cow, yak, buffalo, goat and camel milk [9], and peste des petits ruminants virus (PPRV)-infected Vero cells [10], based on the isobaric tags for relative and absolute quantification (iTRAQ) method. In addition, this technique has also been widely employed to examine the mechanisms of viral infection through comparative investigation of the proteome changes, for example, in the case of Crimean-Congo hemorrhagic fever virus (CCHFV) [11] and bovine respiratory syncytial viruses (BRSV) [12].

However, to the best of our knowledge, no previous study has analyzed the proteomic changes in CPIV3-infected MDBK cells. Proteomic techniques are effective tools to characterize protein expression profiles, and have been widely used to investigate disease-associated proteins [13, 14]. Among current proteomics methods, quantitative high-throughput proteomics approaches are useful for the analysis of infection-associated proteins $[15,16]$. In our current study, we used a quantitative proteomics approach based on an iTRAQ tandem mass spectrometry (MS/MS) technique to identify differentially expressed proteins (DEPs) between CPIV3-infected and mock-infected MDBK cells. The functions of the DEPs were analyzed to determine whether they might be associated with CPIV3 infection [17]. Our findings provide valuable insight into the changes in cellular processes that occur during CPIV3 infection.

\section{Results \\ CPIV3 propagation in MDBK cells}

The kinetics of CPIV3 propagation in MDBK cells were observed by monitoring the CPE at 24,48 and $72 \mathrm{~h}$ post infection (hpi) (Fig. 1a), a minimal CPE was visible at $24 \mathrm{hpi}$, whereas an obvious CPE was observed at $48 \mathrm{hpi}$, and at $72 \mathrm{hpi}$, almost all cells were disrupted. The TCID 50 showed that the viral titer reached $10^{3.5} \mathrm{TCID}_{50} / \mathrm{ml}$ at $24 \mathrm{hpi}$, peaked at $10^{7.0} \mathrm{TCID}_{50} / \mathrm{ml}$ at $72 \mathrm{hpi}$ and then declined (Fig. 1b). To ensure a higher proportion of infected cells and to avoid an excessive CPE, we selected $24 \mathrm{hpi}$ as the time point under our infection conditions for further proteomic analysis.

\section{Identification and annotation of proteins}

We detected 8153 proteins and quantified 4109 proteins, including 28,815 peptides (Additional file 1: Figure S1).
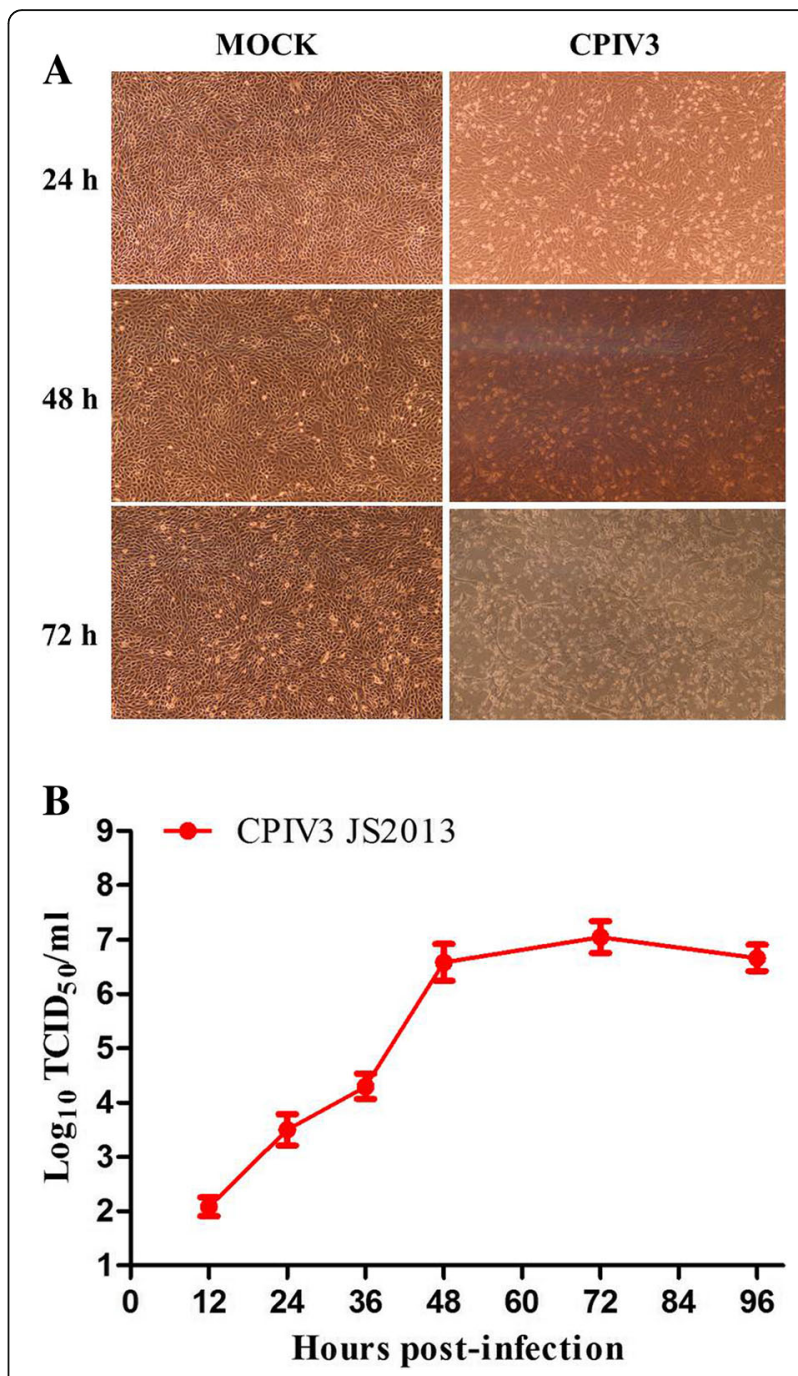

Fig. 1 Confirmation of CPIV3 infection in MDBK cells. a A CPE was observed in MDBK cells at 24, 48 and $72 \mathrm{~h}$ after CPIV3 infection (MOI $=1$ ), with mock-infected cells included as a control. b One-step growth curve of CPIV3 strain JS2013 in MDBK cells

Detected proteins were annotated according to the GO database in the following categories: cellular components (CC), biological processes (BP), and molecular functions (MF) (Additional file 2: Figure S2). The top 20 pathways containing the largest number of proteins among the 8153 proteins were annotated according to KEGG (Additional file 3: Figure S3). Based on the KOG, 830 of the proteins were annotated as being involved in information storage and processing, 1545 were annotated as cellular processes and signaling, 581 were annotated as metabolism, and 699 were annotated as poorly characterized (Additional file 4: Figure S4 and Data Sheet 5). Furthermore, the cutoff criteria considered for the DEPs were set with an adjusted $p$-value of $<0.05$ and a ratio of $>1.2$-fold difference. Among the DEPs, 163 proteins from the two sets of biological replicates overlapped and 
were subsequently adjusted for multiple testing according to the stringent method of Benjamini and Hochberg [18]. Of these, 72 proteins were up-regulated and 91 proteins were down-regulated based on our criteria for the identification of DEPs in the MDBK-infected and mock-infected groups using the iTRAQ-MS/MS approach. Protein ratios were presented as CPIV3-infected/mock-infected. An average $\mathrm{V} / \mathrm{C}$ ratio $>1$ represented up-regulated proteins and an average $\mathrm{V} / \mathrm{C}$ ratio $<1$ represented down-regulated proteins. A list of DEPs information is shown in Table 1. DEPs between the two groups are shown as heat map and scatterplot (Additional file 5: Figure S6 and S7). Finally, the DEPs displaying the greatest increase and decrease in expression in the CPIV3-infected MDBK cells were FAM81B protein (1:0.118) and the DEP displaying the greatest decrease in expression in the CPIV3-infected MDBK cells was carboxypeptidase (1:1.206).

\section{GO analysis of the DEPs}

The molecular functional classes and subcellular locations of the 163 DEPs were analyzed using UniProt and the GO database. The 163 DEPs were annotated into the categories: cellular component, biological process, or molecular function, and the distribution of up-regulated and down-regulated proteins among these GO annotations are shown in Additional file 6: Figure S8. GO enrichment annotation comparisons were performed to elucidate the characteristics of the altered proteins in MDBK cells induced by CPIV3 infection, to determine any associations with virulence and pathogenicity. In terms of biological process annotation, DEPs were mainly involved in cell aggregation, cellular processes, cellular component organization or biogenesis, locomotion, metabolic processes, multicellular organismal processes and reproductive processes; in terms cellular component annotation, DEPs were mainly involved in the cell part, extracellular region part, membrane part, organelle part, protein-containing complex and supramolecular complex; in terms of molecular function annotation, DEPs were mainly involved in binding, catalytic activity, molecular carrier activity and transporter activity (Fig. 2).

\section{KEGG (Kyoto encyclopedia of genes and genomes) pathway analysis of the DEPs}

The KEGG pathway is a collection of pathway maps that represent molecular interactions and reaction networks in cell line. The 93 DEPs identified were annotated, and mapped to a total of six KEGG pathway categories, which included metabolism, disease, genetic information processing, cellular processes, environmental information processing, and organismal systems pathway categories (Additional file 7 Data Sheet 9). The enrichment annotation protein pathway information is shown in
Fig. 3. The results showed that most of the abundant KEGG terms were involved in biological processes such as the p53 signaling pathway, microRNAs in cancer, alanine, aspartate and glutamate metabolism, nitrogen metabolism, the estrogen signaling pathway, mineral absorption and thyroid hormone synthesis. Functional classification by KEGG showed that the upregulated and downregulated proteins could be divided among six distinct functional sets: environmental information processing, cellular processes, metabolism, genetic information processing, organismal systems and human diseases (Fig. 4).

\section{STRING analysis of the relationships between DEPs}

With the goal of exploring the potential protein network connections for the differentially regulated proteins in detail, the STRING tool was used. The differentially regulated proteins were mainly mapped to four functional networks (Fig. 5). A specific network had at least four "focus" proteins (HSPA5, HSPA1B, HSP90B1 and HSPA6). The networks of interest corresponded to: cell-to-cell signaling, hereditary disorder, cell death and survival, cardiovascular disease, cellular developmental, RNA post-transcriptional modification, cellular growth and proliferation.

\section{Confirmation of proteomic data by qRT-PCR}

Alterations in the expression of a protein may be owing to a change in its mRNA levels. To confirm the results of the proteomic analysis by mRNA expression, transcriptional alterations in four selected proteins were measured by qRT-PCR. The qRT-PCR analysis showed that no difference in the ratio of these mRNAs between the CPIV3 infected group and the mock infected group were consistent with those obtained using quantitative proteomics analysis (Fig. 6). The mRNA expression of HSPA5, HSP90B1, HSP A1B and HSPA6 were increased in CPIV3-infected MDBK cells. Therefore, the trends in the mRNA expression were consistent with those in their corresponding proteins.

\section{Western blot analysis of HSPA1B}

We analyzed the expression levels of HSPA1B (up-regulated) in CPIV3-infected MDBK cells (Fig. 7) by western blot at $24 \mathrm{~h}$ and $48 \mathrm{~h}$. Figure 7 shows that HSPA1B was up-regulated in CPIV3-infected MDBK cells at $24 \mathrm{~h}$ and $48 \mathrm{~h}$. The results were consistent with those obtained using the iTRAQ labeled LC-MS/MS system.

\section{Discussion}

Proteomic techniques have become significant methodologies for determining cellular protein interactions and host cellular pathophysiological processes following virus infection $[19,20]$. As a general rule, no important host cell membrane rearrangement or cytoskeleton collapse is observed following virus infection but the point at which a high virus yield is obtained is considered as the best 
Table 1 Statistically significant DEPs identified by iTRAQ analysis of MDBK cells infected with CPIV3

\begin{tabular}{|c|c|c|c|c|c|}
\hline Accession & Protein name & $\begin{array}{l}\text { CPIV3- } \\
\text { infected }\end{array}$ & $\begin{array}{l}\text { Mock- } \\
\text { infected }\end{array}$ & $\begin{array}{l}\text { FC (CPIV3-infected } \\
\text { Vs_Mock-infected) }\end{array}$ & regulate \\
\hline Q0VCX2 & Endoplasmic reticulum chaperone BiP (HSPA5) & 1 & 0.488 & 2.049180328 & up \\
\hline Q95M18 & Endoplasmin (HSP90B1) & 1 & 0.744 & 1.344086022 & up \\
\hline F1MEN8 & Protein disulfide-isomerase A4 (PDIA4) & 1 & 0.816 & 1.225490196 & up \\
\hline E1B748 & Hypoxia up-regulated protein 1 precursor (HYOU1) & 1 & 0.704 & 1.420454545 & up \\
\hline Q27965 & Heat shock 70 kDa protein 1B (HSPA1B) & 1 & 0.793 & 1.261034048 & up \\
\hline A6QR28 & Phosphoserine aminotransferase (PSAT1) & 1 & 0.814 & 1.228501229 & up \\
\hline F1MWU9 & Uncharacterized protein (HSPA6) & 1 & 0.726 & 1.377410468 & up \\
\hline Q3ZCA7 & G protein subunit alpha i3 (GNAI3) & 1 & 0.739 & 1.353179973 & up \\
\hline Q1LZA3 & Asparagine synthetase [glutamine-hydrolyzing] (ASNS) & 1 & 0.721 & 1.386962552 & up \\
\hline P80513 & Mesencephalic astrocyte-derived neurotrophic factor (MANF) & 1 & 0.794 & 1.259445844 & up \\
\hline Q2KHU0 & Phosphoserine phosphatase (PSPH) & 1 & 0.81 & 1.234567901 & up \\
\hline Q3TOL2 & Endoplasmic reticulum resident protein 44 (ERP44) & 1 & 0.765 & 1.307189542 & up \\
\hline Q08DL0 & SLC3A2 protein (SLC3A2) & 1 & 0.78 & 1.282051282 & up \\
\hline A5PK96 & $\mathrm{ACP} 1$ protein $(\mathrm{ACP} 1)$ & 1 & 0.78 & 1.282051282 & up \\
\hline P13909 & Plasminogen activator inhibitor 1 (SERPINE1) & 1 & 0.807 & 1.239157373 & up \\
\hline P68301 & Metallothionein-2 (MT2) & 1 & 0.491 & 2.036659878 & up \\
\hline Q27955 & Voltage-gated potassium channel subunit beta-2 (KCNAB2) & 1 & 0.797 & 1.254705144 & up \\
\hline A5D7C1 & Probable ATP-dependent RNA helicase DDX52 (DDX52) & 1 & 0.814 & 1.228501229 & up \\
\hline A6H797 & MLEC protein (MLEC) & 1 & 0.807 & 1.239157373 & up \\
\hline F1N1R3 & Mitochondrial ribosomal protein L40 (MRPL40) & 1 & 0.824 & 1.213592233 & up \\
\hline E1BPL3 & ATP binding cassette subfamily B member 7 (ABCB7) & 1 & 0.721 & 1.386962552 & up \\
\hline A5PJN8 & Splicing factor 3A subunit 2 (SF3A2) & 1 & 0.551 & 1.814882033 & up \\
\hline Q2KIN6 & Protein Mpv17 (MPV17) & 1 & 0.801 & 1.248439451 & up \\
\hline Q3SZZO & Ribosome biogenesis protein BRX1 homolog (BRIX1) & 1 & 0.799 & 1.251564456 & up \\
\hline A6QLR4 & Flotillin-2 (FLOT2) & 1 & 0.476 & 2.100840336 & up \\
\hline Q17Q12 & $\begin{array}{l}\text { RNA polymerase II subunit A C-terminal domain } \\
\text { phosphatase SSU72 (SSU72) }\end{array}$ & 1 & 0.796 & 1.256281407 & up \\
\hline QOVCS9 & $\begin{array}{l}\text { Ankyrin repeat and MYND domain-containing } \\
\text { protein } 2 \text { (ANKMY2) }\end{array}$ & 1 & 0.812 & 1.231527094 & up \\
\hline A2VE10 & Protein CASC4 (CASC4) & 1 & 0.829 & 1.206272618 & up \\
\hline A7MB19 & NLRX1 protein (NLRX1) & 1 & 0.804 & 1.243781095 & up \\
\hline Q6EVI2 & elF4Gl protein (elF4Gl) & 1 & 0.825 & 1.212121212 & up \\
\hline Q3SZ99 & Peptidylprolyl isomerase (AIP) & 1 & 0.774 & 1.291989664 & up \\
\hline E1BD11 & Chromosome 11 open reading frame 84 (SPINDOC) & 1 & 0.825 & 1.212121212 & up \\
\hline A4FUCO & 395 ribosomal protein L37, mitochondrial (MRPL37) & 1 & 0.815 & 1.226993865 & up \\
\hline Q2TA30 & Ninjurin 1 (NINJ1) & 1 & 0.594 & 1.683501684 & up \\
\hline E1BN60 & Solute carrier family 30 member 1 (SLC30A1) & 1 & 0.77 & 1.298701299 & up \\
\hline Q3T093 & Adaptin ear-binding coat-associated protein 1 (NECAP1) & 1 & 0.83 & 1.204819277 & up \\
\hline G3N3D6 & Phosphoinositide phospholipase C(PLCH1) & 1 & 0.823 & 1.215066829 & up \\
\hline Q2YDF6 & 28 S ribosomal protein S35, mitochondrial(MRPS35) & 1 & 0.809 & 1.236093943 & up \\
\hline Q08DH9 & CCCTC-binding factor(CTCF) & 1 & 0.802 & 1.246882793 & up \\
\hline Q08DK7 & Mitochondrial basic amino acids transporter(SLC25A29) & 1 & 0.798 & 1.253132832 & up \\
\hline F1MBD5 & Surfeit 2(SURF2) & 1 & 0.833 & 1.200480192 & up \\
\hline G3X6N3 & Serotransferrin (TF) & 1 & 0.76 & 1.315789474 & up \\
\hline
\end{tabular}


Table 1 Statistically significant DEPs identified by iTRAQ analysis of MDBK cells infected with CPIV3 (Continued)

\begin{tabular}{|c|c|c|c|c|c|}
\hline Accession & Protein name & $\begin{array}{l}\text { CPIV3- } \\
\text { infected }\end{array}$ & $\begin{array}{l}\text { Mock- } \\
\text { infected }\end{array}$ & $\begin{array}{l}\text { FC (CPIV3-infected } \\
\text { Vs_Mock-infected) }\end{array}$ & regulate \\
\hline F1MG47 & $\begin{array}{l}\text { Peroxisomal N(1)-acetyl-spermine/spermidine oxidase } \\
\text { (PAOX) }\end{array}$ & 1 & 0.706 & 1.416430595 & up \\
\hline E1BH45 & RB1 inducible coiled-coil 1 (RB1CC1) & 1 & 0.682 & 1.46627566 & up \\
\hline E1BMF4 & Kinase D interacting substrate 220 (KIDINS220) & 1 & 0.811 & 1.233045623 & up \\
\hline E1B|11 & ELM2 and Myb/SANT domain containing 1 (ELMSAN1) & 1 & 0.736 & 1.358695652 & up \\
\hline Q5E9T1 & GDP-D-glucose phosphorylase 1 (GDPGP1) & 1 & 0.823 & 1.215066829 & up \\
\hline A7Z023 & CCDC132 protein (CCDC132) & 1 & 0.819 & 1.221001221 & up \\
\hline A6QR26 & UBAP1 protein (UBAP1) & 1 & 0.702 & 1.424501425 & up \\
\hline A5PJZ7 & Histone deacetylase (HDAC6) & 1 & 0.832 & 1.201923077 & up \\
\hline Q148F0 & Ubiquitin-related modifier 1 (URM1) & 1 & 0.402 & 2.487562189 & up \\
\hline F1MRI6 & Lemur tyrosine kinase 2 (LMTK2) & 1 & 0.42 & 2.380952381 & up \\
\hline Q0V882 & Bax inhibitor 1 (TMBIM6) & 1 & 0.766 & 1.305483029 & up \\
\hline G3X6Y2 & Chromosome X open reading frame 38 (CXHXorf38) & 1 & 0.81 & 1.234567901 & up \\
\hline G3MYB9 & UNC homeobox (UNCX) & 1 & 0.793 & 1.261034048 & up \\
\hline G3N0M5 & Uncharacterized protein & 1 & 0.698 & 1.432664756 & up \\
\hline Q3SZN3 & Metalloendopeptidase OMA1, mitochondrial (OMA1) & 1 & 0.304 & 3.289473684 & up \\
\hline A7YWG9 & PHLDA1 protein (PHLDA1) & 1 & 0.654 & 1.529051988 & up \\
\hline AOJNQO & Allograft inflammatory factor 1-like (AIF1L) & 1 & 0.808 & 1.237623762 & up \\
\hline Q2YDD1 & FGFR1 oncogene partner (FGFR1OP) & 1 & 0.664 & 1.506024096 & up \\
\hline F1MN39 & Interferon related developmental regulator 1 (IFRD1) & 1 & 0.521 & 1.919385797 & up \\
\hline Q01190 & Protein FAM81B (FAM81B) & 1 & 0.118 & 8.474576271 & up \\
\hline Q75V95 & Calcitonin receptor-stimulating peptide 1 (CRSP1) & 1 & 0.818 & 1.222493888 & up \\
\hline F1MSI9 & Discs large MAGUK scaffold protein 5 (DLG5) & 1 & 0.795 & 1.257861635 & up \\
\hline E1BFR6 & Transmembrane protease, serine 13 (TMPRSS13) & 1 & 0.827 & 1.209189843 & up \\
\hline E1BC24 & Midasin (MDN1) & 1 & 0.579 & 1.727115717 & up \\
\hline Q08DG0 & Nuclear receptor binding factor 2 (NRBF2) & 1 & 0.434 & 2.304147465 & up \\
\hline Q2KI89 & LisH domain-containing protein ARMC9 (ARMC9) & 1 & 0.411 & 2.433090024 & up \\
\hline F1MNN5 & $\begin{array}{l}\text { Sortilin related VPS10 domain containing receptor } 1 \\
\text { (SORCS1) }\end{array}$ & 1 & 0.759 & 1.317523057 & up \\
\hline A0A140T882 & Uncharacterized protein CLBA1 (CLBA1) & 1 & 0.635 & 1.57480315 & up \\
\hline $\mathrm{F} 1 \mathrm{MH} 73$ & Transmembrane protein 131 (TMEM131) & 1 & 0.793 & 1.261034048 & up \\
\hline Q28037 & Vitamin D3 receptor (VDR) & 1 & 0.826 & 1.210653753 & up \\
\hline F1N2K8 & Periplakin (PPL) & 1 & 1.423 & 0.702740689 & down \\
\hline F6RJG0 & $\begin{array}{l}\text { 3-hydroxy-3-methylglutaryl coenzyme A synthase } \\
\text { (HMGCS1) }\end{array}$ & 1 & 1.371 & 0.729394602 & down \\
\hline Q5KR49 & Tropomyosin alpha-1 chain (TPM1) & 1 & 1.227 & 0.814995925 & down \\
\hline G3MWV5 & Histone cluster $1 \mathrm{H} 1$ family member e (HIST1H1E) & 1 & 1.264 & 0.791139241 & down \\
\hline A7MAZ5 & Histone H1.3 (HIST1H1D) & 1 & 1.258 & 0.79491256 & down \\
\hline Q3SYV6 & Importin subunit alpha (KPNA2) & 1 & 1.22 & 0.819672131 & down \\
\hline Q28178 & Thrombospondin-1 (THBS1) & 1 & 1.406 & 0.711237553 & down \\
\hline F1N3A1 & Thrombospondin-1 (THBS1) & 1 & 1.555 & 0.643086817 & down \\
\hline A4FV94 & KRT6A protein (KRT6A) & 1 & 1.212 & 0.825082508 & down \\
\hline A6QPB5 & PGM1 protein (PGM1) & 1 & 1.272 & 0.786163522 & down \\
\hline G3NoV2 & Keratin 1 (KRT1) & 1 & 1.499 & 0.667111408 & down \\
\hline
\end{tabular}


Table 1 Statistically significant DEPs identified by iTRAQ analysis of MDBK cells infected with CPIV3 (Continued)

\begin{tabular}{|c|c|c|c|c|c|}
\hline Accession & Protein name & $\begin{array}{l}\text { CPIV3- } \\
\text { infected }\end{array}$ & $\begin{array}{l}\text { Mock- } \\
\text { infected }\end{array}$ & $\begin{array}{l}\text { FC (CPIV3-infected } \\
\text { Vs_Mock-infected) }\end{array}$ & regulate \\
\hline E1BNE7 & Caveolae associated protein 1 (CAVIN1) & 1 & 1.213 & 0.824402308 & down \\
\hline Q3YJF3 & MHC class I antigen (Fragment) (BoLA) & 1 & 1.277 & 0.783085356 & down \\
\hline Q2HJJO & Kinesin light chain 4 (KLC4) & 1 & 1.209 & 0.827129859 & down \\
\hline F1MX88 & Solute carrier family 25 member 13 (SLC25A13) & 1 & 1.212 & 0.825082508 & down \\
\hline F1 N688 & V-type proton ATPase subunit B, kidney isoform (ATP6V1B1) & 1 & 1.352 & 0.73964497 & down \\
\hline Q0VCZ8 & Acyl-CoA synthetase long-chain family member 1 (ACSL1) & 1 & 1.333 & 0.750187547 & down \\
\hline A6QNZ7 & $\begin{array}{l}\text { Keratin } 10 \text { (Epidermolytic hyperkeratosis; keratosis } \\
\text { palmaris et plantaris) (KRT10) }\end{array}$ & 1 & 1.387 & 0.720980534 & down \\
\hline F1N4K3 & Uncharacterized protein & 1 & 1.474 & 0.678426052 & down \\
\hline F1MTJ9 & Terpene cyclase/mutase family member (LSS) & 1 & 1.243 & 0.804505229 & down \\
\hline Q867D1 & Stearoyl-CoA desaturase (Scd) & 1 & 1.427 & 0.700770848 & down \\
\hline $\mathrm{F} 1 \mathrm{MH} 31$ & Nucleoporin 214 (NUP214) & 1 & 1.241 & 0.805801773 & down \\
\hline G3N1R5 & Uncharacterized protein & 1 & 1.454 & 0.687757909 & down \\
\hline Q32PA5 & Ubiquitin-conjugating enzyme E2 C (UBE2C) & 1 & 1.589 & 0.629326621 & down \\
\hline Q0P5J6 & Keratin, type I cytoskeletal 27 (KRT27) & 1 & 1.375 & 0.727272727 & down \\
\hline A7MB38 & SFRS4 protein (SRSF4) & 1 & 1.22 & 0.819672131 & down \\
\hline A7YW33 & DNA polymerase delta interacting protein 3 (POLDIP3) & 1 & 1.267 & 0.789265983 & down \\
\hline Q3ZCI0 & $\begin{array}{l}\text { Coiled-coil-helix-coiled-coil-helix domain containing } 2 \\
\text { (CHCHD9) }\end{array}$ & 1 & 1.298 & 0.770416025 & down \\
\hline E1BJC9 & Uncharacterized protein (C18H19orf33) & 1 & 1.24 & 0.806451613 & down \\
\hline A5D7N6 & Kinesin-like protein (KIF23) & 1 & 1.373 & 0.728332119 & down \\
\hline $\mathrm{F} 2 \mathrm{Z} 4 \mathrm{H} 2$ & Non-histone chromosomal protein HMG-17 (HMGN2) & 1 & 1.242 & 0.805152979 & down \\
\hline A3KLR9 & Superoxide dismutase (SOD3) & 1 & 1.36 & 0.735294118 & down \\
\hline G8JKY5 & Thymosin beta-4 (TMSB4X) & 1 & 1.547 & 0.646412411 & down \\
\hline Q08DI5 & Ras-related protein Rap-2c (RAP2C) & 1 & 1.207 & 0.828500414 & down \\
\hline A4IF70 & GPR56 protein (GPR56) & 1 & 1.233 & 0.811030008 & down \\
\hline P15103 & Glutamine synthetase (GLUL) & 1 & 1.265 & 0.790513834 & down \\
\hline E1BKT0 & Leucine zipper protein 1 (LUZP1) & 1 & 1.353 & 0.7390983 & down \\
\hline F1MFW9 & Keratin 24 (KRT24) & 1 & 2.313 & 0.432338954 & down \\
\hline Q0VC74 & Trimethyllysine dioxygenase, mitochondrial (TMLHE) & 1 & 1.217 & 0.821692687 & down \\
\hline F1MLZ1 & Cytochrome b reductase 1 (CYBRD1) & 1 & 1.252 & 0.798722045 & down \\
\hline F1MP14 & Forkhead box K1 (FOXK1) & 1 & 1.208 & 0.82781457 & down \\
\hline F1MYS2 & FCH domain only 2 (FCHO2) & 1 & 1.253 & 0.798084597 & down \\
\hline Q3T0J9 & $\begin{array}{l}\text { Guanine nucleotide-binding protein-like 3-like protein } \\
\text { (GNL3L) }\end{array}$ & 1 & 1.336 & 0.748502994 & down \\
\hline Q2NKZ9 & Carboxypeptidase (SCPEP1) & 1 & 1.206 & 0.829187396 & down \\
\hline F1N6L1 & Valyl-tRNA synthetase 2, mitochondrial (VARS2) & 1 & 1.272 & 0.786163522 & down \\
\hline G5E5Q8 & SET binding factor 1 (SBF1) & 1 & 1.286 & 0.777604977 & down \\
\hline Q2KHW7 & Regulator of G-protein signaling 10 (RGS10) & 1 & 1.219 & 0.820344545 & down \\
\hline F1N4R2 & Uncharacterized protein (MORF4L1) & 1 & 1.222 & 0.818330606 & down \\
\hline Q5E9Q1 & Protein O-glucosyltransferase 1 (POGLUT1) & 1 & 1.234 & 0.810372771 & down \\
\hline Q29RZ9 & WD repeat-containing protein 92 (WDR92) & 1 & 1.26 & 0.793650794 & down \\
\hline F1N5R4 & Conserved oligomeric Golgi complex subunit 8 (COG8) & 1 & 1.271 & 0.786782061 & down \\
\hline F1ML71 & Nedd4 family interacting protein 2 (NDFIP2) & 1 & 1.254 & 0.797448166 & down \\
\hline
\end{tabular}


Table 1 Statistically significant DEPs identified by iTRAQ analysis of MDBK cells infected with CPIV3 (Continued)

\begin{tabular}{|c|c|c|c|c|c|}
\hline Accession & Protein name & $\begin{array}{l}\text { CPIV3- } \\
\text { infected }\end{array}$ & $\begin{array}{l}\text { Mock- } \\
\text { infected }\end{array}$ & $\begin{array}{l}\text { FC (CPIV3-infected } \\
\text { Vs_Mock-infected) }\end{array}$ & regulate \\
\hline G3 N266 & G protein signaling modulator 1 (GPSM1) & 1 & 1.235 & 0.809716599 & down \\
\hline F1NOKO & Collagen alpha-1(XI) chain (COL11A1) & 1 & 1.212 & 0.825082508 & down \\
\hline F1MGF2 & Chromodomain helicase DNA binding protein 1 (CHD1) & 1 & 1.254 & 0.797448166 & down \\
\hline A6QQK2 & MAP3K7IP1 protein (MAP3K7IP1) & 1 & 1.339 & 0.74682599 & down \\
\hline E1BDA1 & Ras and Rab interactor 1 (RIN1) & 1 & 1.29 & 0.775193798 & down \\
\hline E1B8R7 & $\begin{array}{l}\text { HPS5, biogenesis of lysosomal organelles complex } 2 \\
\text { subunit } 2 \text { (HPS5) }\end{array}$ & 1 & 1.252 & 0.798722045 & down \\
\hline A8E646 & CARD11 protein (CARD11) & 1 & 1.222 & 0.818330606 & down \\
\hline Q32KL9 & B-cell receptor-associated protein 29 (BCAP29) & 1 & 1.435 & 0.696864111 & down \\
\hline E1BGG6 & Regulatory factor X5 (RFX5) & 1 & 1.233 & 0.811030008 & down \\
\hline Q3TON3 & Calcium load-activated calcium channel (TMCO1) & 1 & 1.295 & 0.772200772 & down \\
\hline E1BC89 & Oxysterol-binding protein (OSBPL5) & 1 & 1.241 & 0.805801773 & down \\
\hline F1MQ45 & $\begin{array}{l}\text { Solute carrier organic anion transporter family member } \\
\text { (SLCO2A1) }\end{array}$ & 1 & 1.234 & 0.810372771 & down \\
\hline Q32P76 & Small EDRK-rich factor 1 (SERF1) & 1 & 1.447 & 0.691085003 & down \\
\hline A6QQS5 & WHSC2 protein (WHSC2) & 1 & 1.289 & 0.77579519 & down \\
\hline F1MNT2 & Protein RTF2 homolog (RTF2) & 1 & 1.278 & 0.782472613 & down \\
\hline F1MEY2 & $\begin{array}{l}\text { Enoyl-[acyl-carrier-protein] reductase, mitochondrial } \\
\text { (MECR) }\end{array}$ & 1 & 1.387 & 0.720980534 & down \\
\hline A6QNX2 & DPP7 protein (DPP7) & 1 & 1.287 & 0.777000777 & down \\
\hline E1BE80 & Transmembrane protein 236 (TMEM236) & 1 & 1.247 & 0.801924619 & down \\
\hline A4IFD1 & PDCD4 protein (PDCD4) & 1 & 1.209 & 0.827129859 & down \\
\hline A1A4R8 & Cell division cycle protein 23 homolog (CDC23) & 1 & 1.267 & 0.789265983 & down \\
\hline E1BG49 & Centromere protein E (CENPE) & 1 & 1.324 & 0.755287009 & down \\
\hline P07926 & $\begin{array}{l}\text { ATP synthase } F(0) \text { complex subunit } C 2 \text {, mitochondrial } \\
\text { (ATP5MC2) }\end{array}$ & 1 & 1.497 & 0.668002672 & down \\
\hline Q402A0 & Aggrus (PDPN) & 1 & 1.293 & 0.773395205 & down \\
\hline Q17Q11 & Trafficking protein particle complex subunit 1 (TRAPPC1) & 1 & 1.265 & 0.790513834 & down \\
\hline E1BKA4 & Uncharacterized protein (HAUS4) & 1 & 1.3 & 0.769230769 & down \\
\hline Q2KHT6 & F-box only protein 32 (FBXO32) & 1 & 1.227 & 0.814995925 & down \\
\hline F1MS44 & Doublecortin domain containing 2 (DCDC2) & 1 & 1.277 & 0.783085356 & down \\
\hline E1BIR2 & Dipeptidase (DPEP2) & 1 & 1.211 & 0.825763832 & down \\
\hline A5PKA5 & Sorting nexin-27 (SNX27) & 1 & 1.31 & 0.763358779 & down \\
\hline $\mathrm{A} 6 \mathrm{H} 7 \mathrm{C} 1$ & MORF4L2 protein (MORF4L2) & 1 & 1.213 & 0.824402308 & down \\
\hline A6QLZ5 & Protein FAM177A1 (FAM177A1) & 1 & 1.23 & 0.81300813 & down \\
\hline P13384 & Insulin-like growth factor-binding protein 2 (IGFBP2) & 1 & 1.748 & 0.57208238 & down \\
\hline A5D974 & $\begin{array}{l}\text { Acyl-Coenzyme A dehydrogenase family, member } 9 \\
\text { (ACAD9) }\end{array}$ & 1 & 1.217 & 0.821692687 & down \\
\hline F1N2N9 & Coiled-coil domain containing 114 (CCDC114) & 1 & 1.224 & 0.816993464 & down \\
\hline $\mathrm{E} 1 \mathrm{BBH} 4$ & Protein unc-93 homolog B1 (UNC93B1) & 1 & 1.666 & 0.600240096 & down \\
\hline A5PJX0 & F-box protein 22 (FBXO22) & 1 & 1.272 & 0.786163522 & down \\
\hline E1BEG4 & Zinc finger FYVE-type containing 16 (ZFYVE16) & 1 & 1.225 & 0.816326531 & down \\
\hline E1BEl6 & ATM serine/threonine kinase (ATM) & 1 & 1.507 & 0.663570007 & down \\
\hline P0C914 & Overexpressed in colon carcinoma 1 protein homolog & 1 & 1.213 & 0.824402308 & down \\
\hline
\end{tabular}




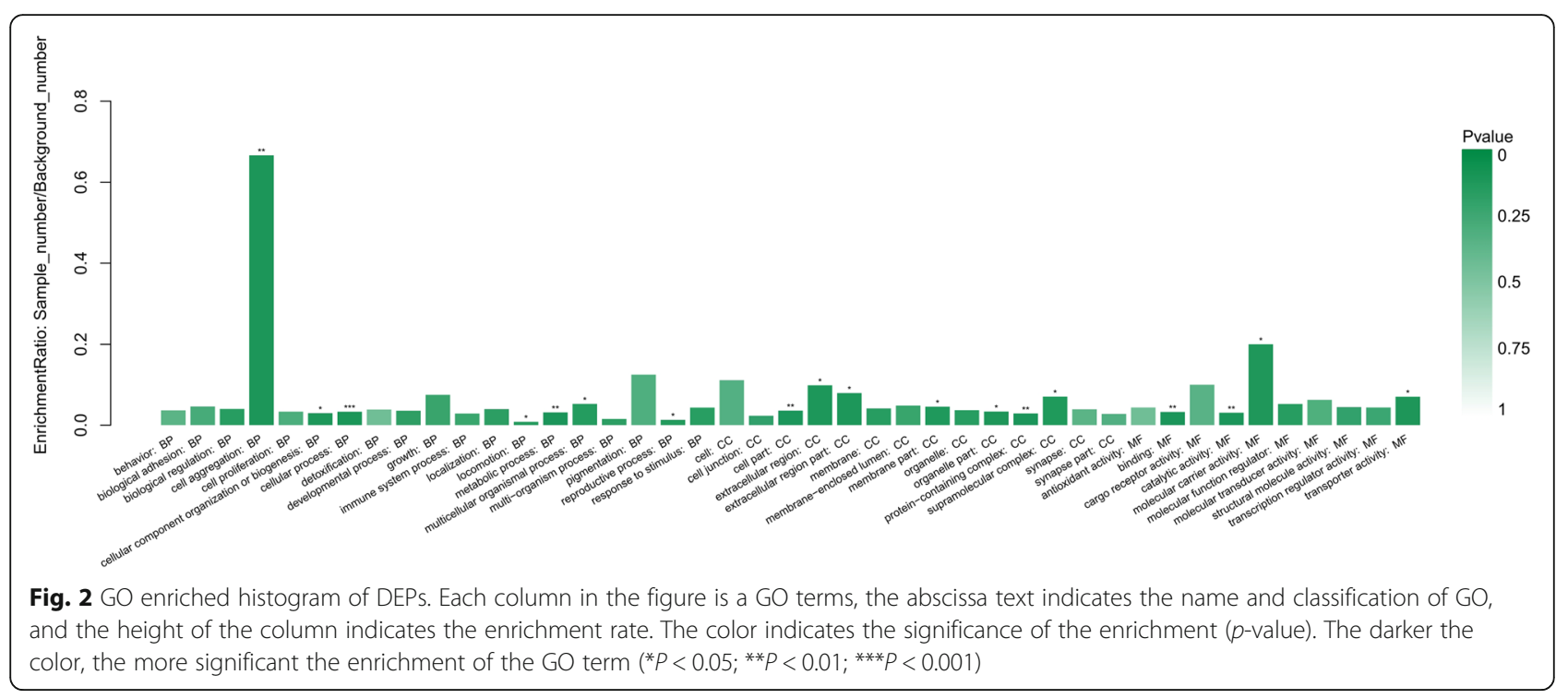

time for proteomic analysis [21, 22]. Taking this substantial evidence into consideration, cell samples at $24 \mathrm{hpi}$ were chosen for further proteomic analysis. Based on our study, the expression levels of 163 DEPs were found to be significantly altered in CPIV3-infected cells. The results of GO, KEGG pathway and STRING analysis predicted that these DEPs pertaining to different types of functional categories and signal pathways. Western blot and qRT-PCR were also applied to validate some differential proteins at the mRNA and protein levels. To date, no analysis has been reported of the differential proteomes of MDBK cells infected with CPIV3. Our data may provide an overview of the proteins altered in expression during the host response to CPIV3 infection and may provide insight in the process of CPIV3 pathogenesis.
Studies have shown that HSPs may play an important role in virus host cell interactions during in vivo and in vitro infection [23, 24]. Inhibitors of HSP90 can inhibit herpes simplex virus type 1 (HSV-1) infection [25]. Bovine viral diarrhea virus (BVDV) structural proteins comprise the $\mathrm{C}$ nucleocapsid protein and three envelope glycoproteins, Erns, E1 and E2 [26]. A previous study found that HSP110 enhanced the presentation of E2 to CD4 T cells in vitro to improve the immunogenicity of an E2 vaccine in cattle [27]. Previous work demonstrated that HSP70 is actively released into the extracellular milieu and acts as a cytokine and peptide adjuvant, thereby promoting both the innate and adaptive immune responses [28]. In our analysis, four proteins (HSPA5, HSPA1B, HSP90B1 and HSPA6) were identified

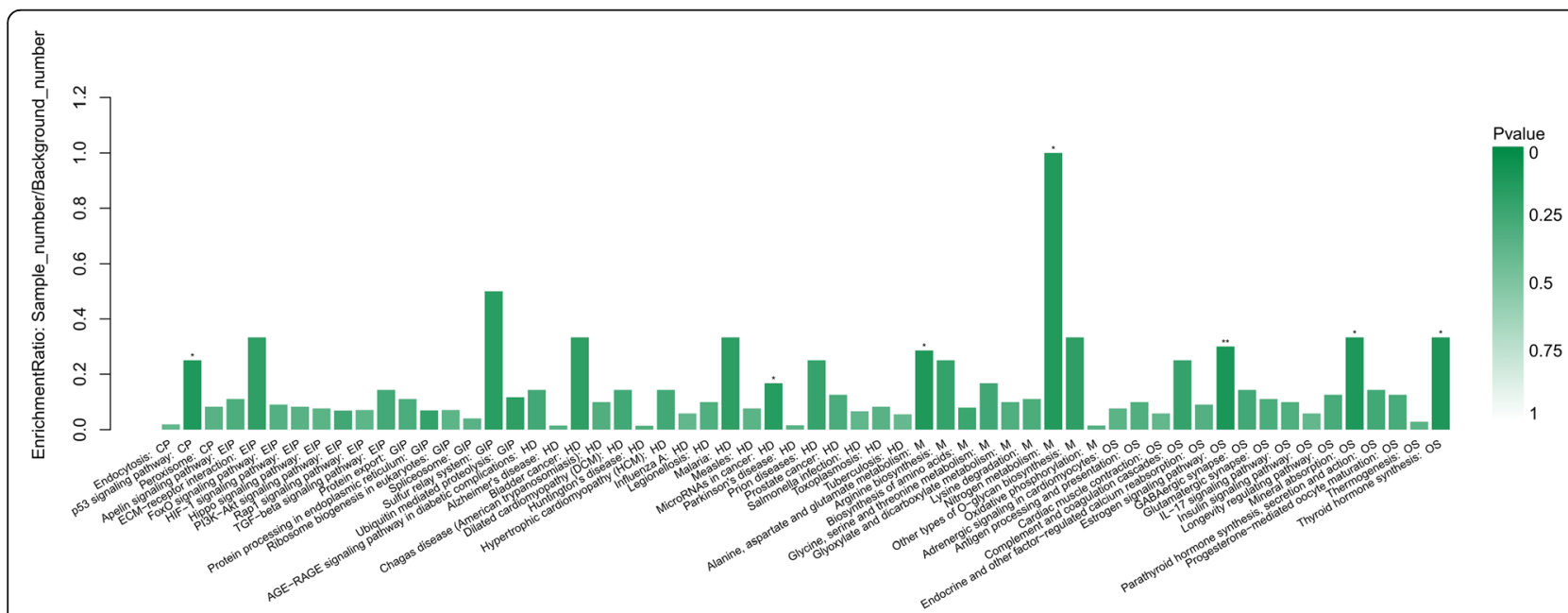

Fig. 3 KEGG enrichment annotation of the DEPs. Each column in the figure is a pathway. The abscissa text indicates the name and classification of the pathway, and the height of the column indicates the enrichment rate. The color indicates the significance of the enrichment ( $p$-value). The darker the color, the more significant the enrichment of the pathway ${ }^{*} P<0.05 ;{ }^{* *} P<0.01$; $\left.{ }^{* *} P<0.001\right)$ 


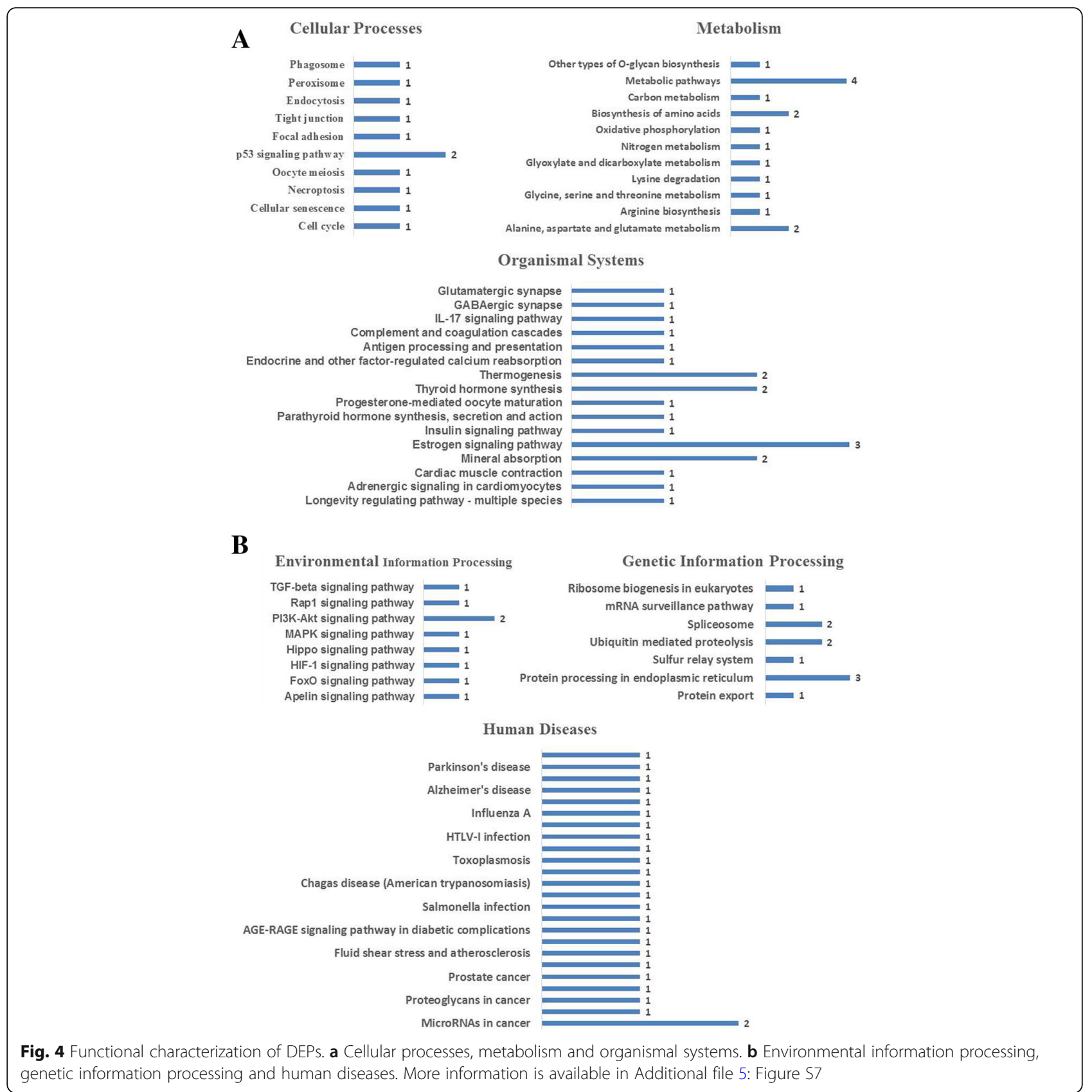

following CPIV3 infection. HSP90B1 is proposed to be associated with poor survival from hepatocellular carcinoma (HCC), whereas high levels of HSPA5 and HSPA6 may be associated with earlier recurrence of HCC [29]. HSPA1B, also known as heat shock protein 72 , is a member of the HSP70 family. HSP70 expression levels rapidly increased in response to cellular stresses such as heat shock, or in response to certain viral infections [30-33].

In the current study, HSP70 was rarely detected in the mock-infected group, whereas it was notably present in the CPIV3 group. CPIV3 infection resulted in the up-regulated secretion of exosomes and packaging of the viral proteins into exosomes, and these results suggested that CPIV3 infection may enhance HSP70-mediated exosome release (unpublished data). In addition, HSP70 is actively released into the extracellular milieu, thereby promoting innate and adaptive immune responses [34]. In this study, HSPA5, HSPA1B, HSP90B1 and HSPA6 were up-regulated at 24 hpi to various degrees following CPIV3 -infection of MDBK cells. Different expression levels of HSPA1B were detected by western blot analysis at $24 \mathrm{hpi}$ and $48 \mathrm{hpi}$ after CPIV3 -infection of MDBK cells. This may indicate that HSPA1B affects the proliferation of CPIV3 in MDBK cells. HSPA1B is an endogenous ligand for toll-like receptor 


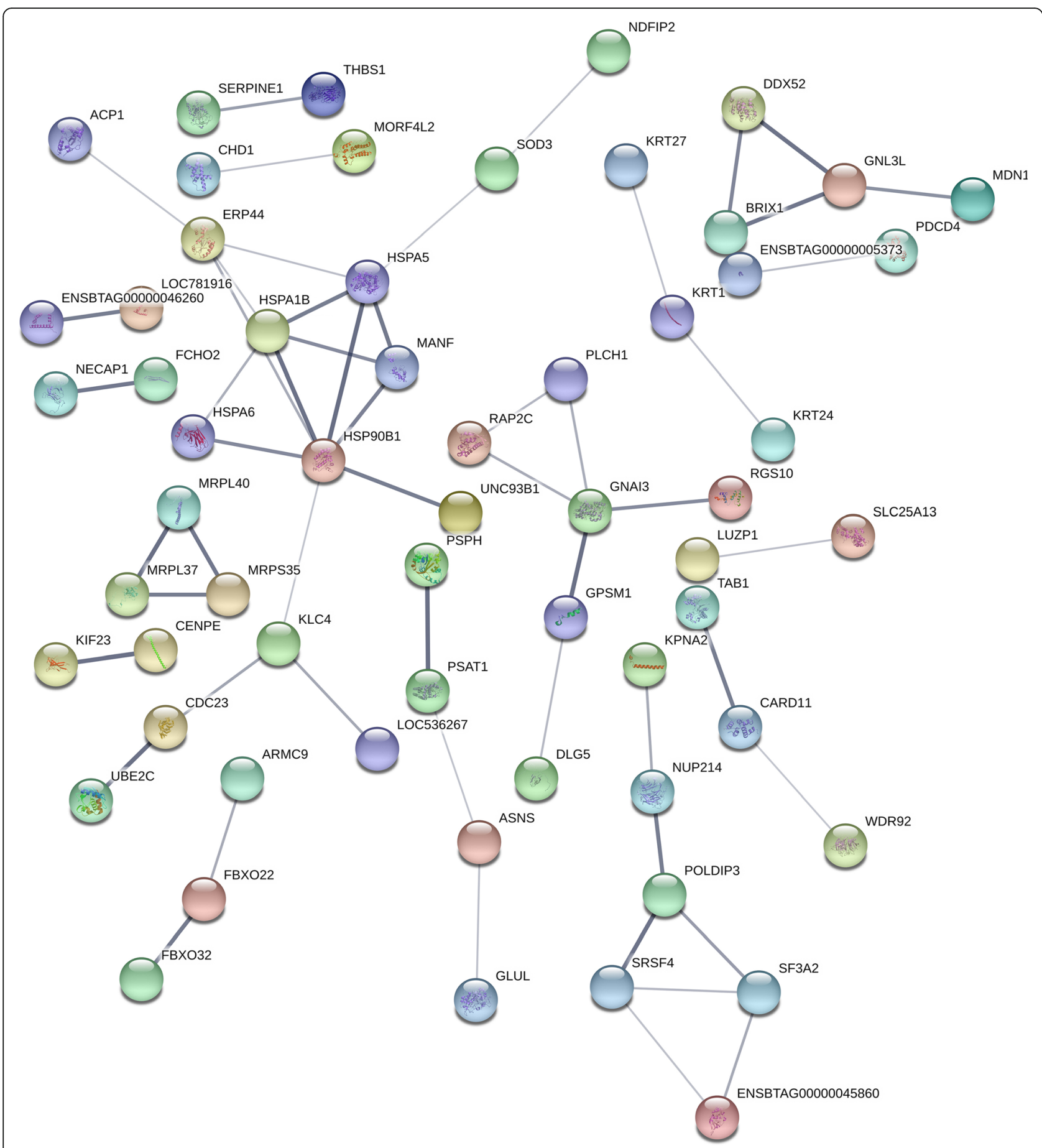

Fig. 5 Specific network analysis of proteins significantly altered in CPIV3-infected cells. The network of DEPs with STRING analysis. Each node represents a protein in the graph, each line represents the interaction between proteins, and the wider the line, the closer the relationship

TLR4, thereby stimulating innate immunity [35], and HSPA1B regulates the NF- $\mathrm{BB}$ pathway via TLR2 and TLR4 in fibroblasts. However, fibroblasts and macrophages interact with each other to mediate the immune response. Activation of the NF-kB pathway then results to in enhanced secretion of pro-inflammatory cytokines (TNF- $\alpha$, IL- 6 and
IL-1 $\beta$ ) and neutrophil chemoattractant MIP-2 and Cxcl1 from macrophages [36]. This evidence indicates that HSPA1B may be associated with the proliferation of CPIV3 in MDBK cells through an ability to interact with key components of the NF- $\mathrm{KB}$ pathway, moreover, those involved in innate immunity, but the detailed mechanism remains 


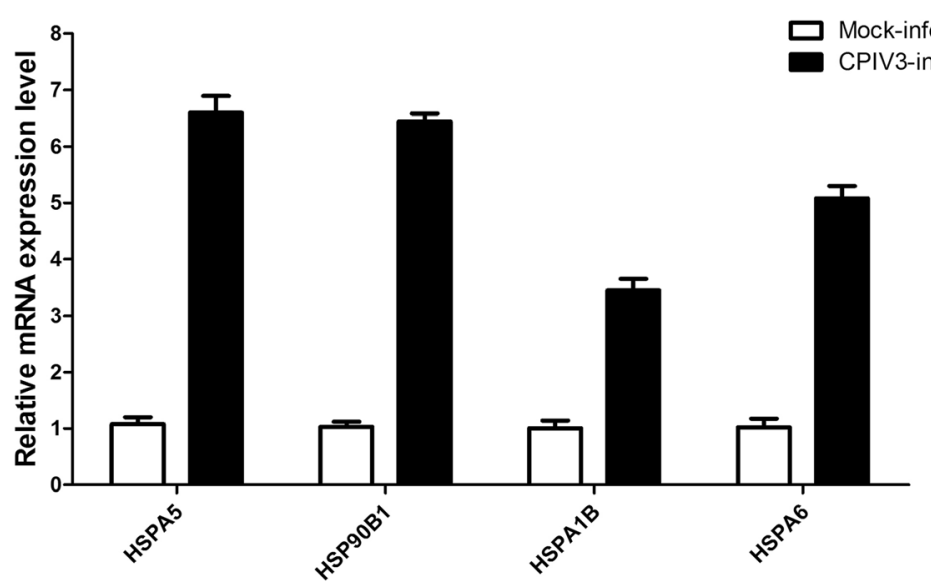

Fig. 6 qRT-PCR analysis of mRNA expression in the CPIV3-infected and mock-infected groups. The cells were collected at 24 hpi for qRT-PCR to analyze the relative mRNA expression of the HSPA5, HSP90B1, HSPA1B and HSPA6 genes. The GAPDH gene was included as a control housekeeping gene for the normalization of samples. Error bars represent standard deviations

unknown. However, the detailed functions of these pathways and proteins changes in CPIV3 infection therefore requires further verification.

\section{Conclusions}

The proteomic changes in CPIV3-infected MDBK cells were analyzed using iTRAQ combined with LC-MS/MS. To the best of our knowledge, this is the first time proteomics has been used to explore the virus-host protein interaction network in CPIV3-infected MDBK cells. The results revealed 163 DEPs, among which 72 were upregulated and 91 were down-regulated. In addition, four DEPs were validated by qRT-PCR and HSPA1B was validated by western blot analysis. These results were consistent with those of label-free LC-MS analysis. Our analyses of the DEPs were descriptive, and further functional investigations are required to elucidate the

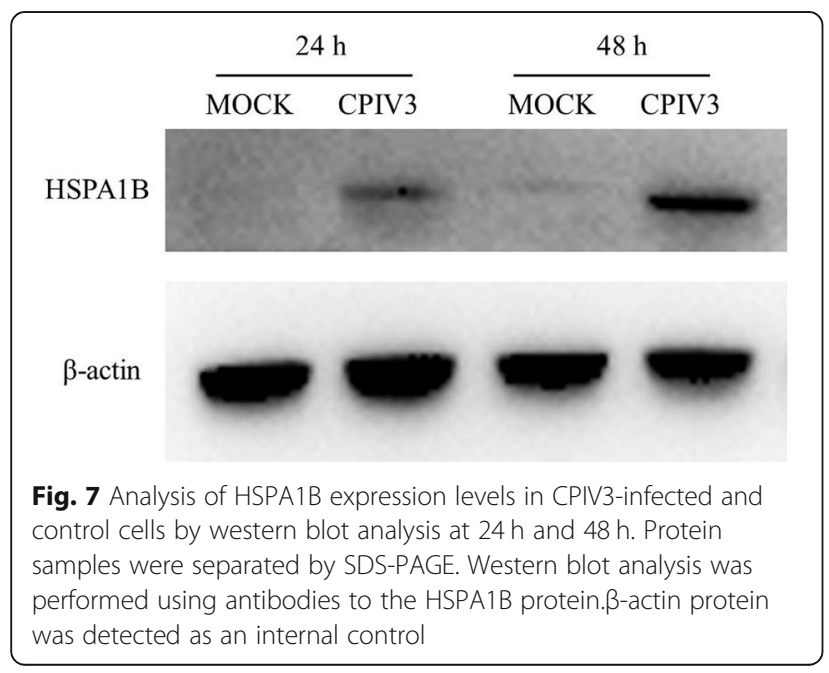

pathogenic mechanisms and cellular responses to CPIV3 infection.

\section{Methods}

Cell culture and virus infection

CPIV3 strain JS2013 isolated in Jiangsu Province was used for virus infection. MDBK cells were cultured in Dulbecco's modified Eagle's medium (DMEM; Sigma, CA, USA) supplemented with $10 \%$ fetal bovine serum (FBS; HyClone, UT, USA), at $37^{\circ} \mathrm{C}$ in an atmosphere of $5 \% \mathrm{CO}_{2}$ [2]. When the cells grow to $70-80 \%$ confluence, they were inoculated with CPIV3 at a multiplicity of infection (MOI) of 1 . After $1 \mathrm{~h}$ of adsorption, infected cells were maintained in fresh medium containing $2 \%$ FBS. Uninfected cells were used as a control. The CPIV3- or mock-infected cells were collected at $24 \mathrm{hpi}$. Viral propagation was confirmed by the observation of a cytopathic effect (CPE).

\section{Protein sample preparation and labeling with ITRAQ reagent}

The CPIV3- and mock-infected cell samples were washed three times with cold phosphate-buffered saline (PBS) and then treated with lysis buffer containing $8 \mathrm{M}$ urea, $4 \%$ CHAPS, $2 \mathrm{M}$ thiourea, and $30 \mathrm{mM}$ Tris- $\mathrm{HCl}$ on ice for $30 \mathrm{~min}$ until the cell line were completely lysed. The supernatant was collected by centrifugation at $12000 \times g$ for $30 \mathrm{~min}$ at $4{ }^{\circ} \mathrm{C}$ after ultrasonication treatment for $2 \mathrm{~min}$. The protein concentration in the supernatants was quantified using the Bradford protein assay. After reduction and cysteine-blocking as described in the iTRAQ protocol (AB Sciex, Concord, ON, USA), solutions containing $100 \mu \mathrm{g}$ protein were digested overnight at $37^{\circ} \mathrm{C}$ with sequence grade modified trypsin (Promega, Madison, WI, USA) and then labeled with 
different iTRAQ tags. The labeled samples were then mixed and dried with a rotary vacuum concentrator.

\section{LC-MS analysis}

Ten microliters $(\mu \mathrm{l})$ of each fraction were analyzed by $\mathrm{Q}$ Exactive (Thermo, USA) mass spectrometer coupled to a Proxeon Biosystem Easy-nLC 1200 (Thermo Fisher Scientific, Waltham, MA, USA) in the LC-MS experiments. The peptide mixture $(5 \mathrm{~g})$ was loaded onto a C18 column $(75 \mu \mathrm{m} \times 25 \mathrm{~cm}$, Thermo,USA $)$ packed with $\mathrm{RP}-\mathrm{C} 18(5 \mathrm{~m})$ resin in buffer A ( $2 \% \mathrm{ACN}$ with $0.1 \%$ formic acid), and eluted with a linear gradient of buffer $B$ (80\% ACN with $0.1 \%$ formic acid) at a flow rate of 300 $\mathrm{nl} / \mathrm{min}$ for $120 \mathrm{~min}$ using IntelliFlow technology. The equate underwent electrospray ionization for LC-MS analysis. The MS/MS instrument was run in the peptide recognition mode, and the spectra were acquired using a data-dependent top-20 method based on the selection of the most abundant precursor ions from the survey scan $(350-1300 \mathrm{~m} / \mathrm{z})$ for HCD fragmentation. Determination of the target value was based on the predictive automatic gain control, and the dynamic exclusion duration was $18 \mathrm{~s}$. Survey scans were acquired at a resolution of 70,000 at $\mathrm{m} / \mathrm{z} 200$, and the resolution for the HCD spectra was set to 17,500 at $\mathrm{m} / \mathrm{z} 200$. The normalized collision energy was $30 \mathrm{eV}$, and the underfill ratio, which specifies the minimum percentage of the target value likely to be reached at maximum fill time, was defined as $0.1 \%$. Thermo Xcalibur 4.0 (Thermo, USA) was used to collect MS analysis data via DDA mode.

\section{Data analysis}

The MS data were analyzed using Proteome Discoverer ${ }^{\mathrm{Tm}}$ software 2.1. When the library was searched, the raw file was submitted to the Proteome Discoverer server searched against the Uniprot Bos taurus database (197,939 total sequences, downloaded April 26, 2018). The following parameters were used for protein identification: a precursor mass tolerance of $20 \mathrm{ppm}$; a fragment mass tolerance of $0.05 \mathrm{Da}$; trypsin digestion; max. Missed cleavage sites of 2; the variable dynamic modifications included oxidation (M), iTRAQ8plex $(\mathrm{Y})$ and acetyl (protein $\mathrm{N}$-terminus), and the fixed static modifications included carbamidomethyl (C), iTRAQ8plex (K) and iTRAQ8plex (N-term). The cutoff for the global false discovery rate (FDR) for peptide and protein identification was set to 0.01 . The value of the quantitative ratio for each protein relative to the internal reference was calculated, and averaged to obtain the quantitative ratio $(\mathrm{V} / \mathrm{C})$ of the proteins identified in the treatment groups [37]. Proteins with a fold change $>1.2$ and a $p$-value $<$ 0.05 were considered to shows significantly different expression. Auto bias-correction was executed to decrease the artificial error. Statistical analysis was performed using Excel 2007 software. The DEPs were annotated using gene ontology (GO) and KEGG database. The Cluster of Orthologous Groups of proteins (COG or KOG) were retrieved, and mapped to pathways in the KEGG database [38]. In addition, DEPs were analyzed using STRING for predicting functional association networks of proteins.

\section{CPIV3 yield quantification}

MDBK cells were seeded in 96-well plates and incubated for $24 \mathrm{~h}$. Then, CPIV3 samples were 10 -fold serially diluted and added to each well in quadruplicate. MDBK cells exhibit CPE were scored positive for viral growth and the $\mathrm{TCID}_{50}$ was calculated by the Reed-Muench method [39].

\section{mRNA quantitation by qRT-PCR}

Total cellular RNA was extracted from the CPIV3-infected and mock-infected MDBK cells using Transzol UP reagent (Transgen Co. Ltd., Beijing, China) according to the manufacturer's protocol. Specific primers for amplifying various genes were as follows: for GAPDH mRNA analysis, 5'-GATTGTCAGCAATGCCTCCT-3' (forward) and 5'-G GTCATA AGTCCCTCCACGA-3' (reverse) were used; for HSPA5 mRNA analysis, 5'-GTGCCCACCA AGAAGTCT CA-3' (forward) and 5'-CTTTCGTCAGGGGTCGTTC A-3' (reverse) were used; for HSP90B1 mRNA analysis, 5' TCAAGGGTGTTGTGGACTCG-3' (forward) and 5'-GC T GAAGTGTCTCACGGG AA-3' (reverse) were used; for HSPA1B mRNA analysis, 5'-AGTC GGACATGAAGC ACTGG-3' (forward) and 5'-TCACCTGCACCTTAGGC TTG-3' (reverse) were used; and for HSPA6 mRNA analysis, 5' -AGGACAGGCGCAAAGTACAA-3' (forward) and 5'-TGCTCCAGCTCCCTCTTTTG-3' (reverse) were used. GAPDH was employed as an internal reference gene. The first-strand cDNA was synthesized via PrimeScript ${ }^{\mathrm{ma}}$ RT Master Mix (TaKaRa, Dalian, China). Then qRT-PCR was performed using the SYBR Premix Ex Taq ${ }^{\mathrm{Tm}}$ II Kit (TaKaRa) on an ABI Step One thermocycler (Applied Biosystems, CA, USA). The relative expression level of each mRNA was calculated by the $2^{-\Delta \Delta c t}$ method. Three independent biological replicates were performed for each gene.

\section{Western blot analysis}

To further verify the variation in the DEPs identified by the proteomic approaches, HSPA1B was selected for western blot analysis. The CPIV3- and mock-infected cells were collected at 24 and 48 hpi. Equivalent amounts of cell lysate from each sample were collected. After measuring the protein concentrations, equivalent amounts of cellular proteins were separated by SDS-PAGE and transferred onto nitrocellulose PVDF membranes (Millipore, USA). The membranes were incubated overnight at $4{ }^{\circ} \mathrm{C}$ with primary rabbit polyclonal antibodies of anti-HSPA1B (Biyotime, 
Shanghai, China). Then the membranes were further incubated for $1 \mathrm{~h}$ with horseradish peroxidase-conjugated goat anti-rabbit secondary antibody (BIOSS, Beijing, China). The protein bands were detected using the ECL Detection Kit (Vazyme, Nanjing, China). $\beta$-actin protein was used as an internal control.

\section{Additional files}

\author{
Additional file 1: Figure S1. Information on the detected proteins in \\ CPIV3-infected MDBK cells (JPG $357 \mathrm{~kb}$ ) \\ Additional file 2: Figure S2. Detected proteins were annotated in the \\ GO database (JPG $1406 \mathrm{~kb}$ ) \\ Additional file 3: Figure S3. The top 20 pathways annotated by KEGG \\ (JPG $738 \mathrm{~kb}$ )
}

Additional file 4: Figure S4 and Data Sheet 5. Proteins were annotated based on the KOG (ZIP $669 \mathrm{~kb}$ )

Additional file 5: Figure $\mathbf{S 6}$ and $\mathbf{5 7}$ Heat map and scatterplot (ZIP $1116 \mathrm{~kb})$

Additional file 6: Figure S8. GO annotations for the up-regulated and down-regulated proteins (JPG $2482 \mathrm{~kb}$ )

Additional file 7: Data Sheet 9. The 93 DEPs were annotated into six KEGG pathway categories (XLS $32 \mathrm{~kb}$ )

\section{Abbreviations}

COG: Cluster of orthologous groups of proteins; CPE: Cytopathic effect; CPIV3: Caprine parainfluenza virus type 3; DEPs: Differentially expressed proteins; DMEM: Dulbecco's modified Eagle's medium; FDR: False discovery rate; GO: Gene ontology; HSPs: Heat shock proteins; iTRAQ: Isobaric tags for relative and absolute quantification; KEGG: Kyoto encyclopedia of genes and genomes; MDBK: Madin-Darby bovine kidney; MOI: Multiplicity of infection

\section{Acknowledgments}

We thank Kate Fox, DPhil, from Liwen Bianji, Edanz Group China (https://www.liwenbianji.cn/), for editing the English text of a draft of this manuscript.

\section{Funding}

This work was supported by the National Natural Science Foundation of China (31702272, 31802196), Natural Science Foundation of Jiangsu Province, China (BK20170595), Natural Science Foundation of Shandong Province, China (ZR2016CP08), and the National Key R\&D Program of China (2016YFD0500908, 2018YFD0502100). The funders had no role in study design, in the collection, analysis and interpretation of data, in the writing the manuscript, or in the decision to submit the article for publication.

\section{Availability of data and materials}

The datasets contained in this study are available from the corresponding author upon request.

\section{Authors' contributions}

$\mathrm{CZ}$ and $\mathrm{JL}$ took part in all the experiments and wrote the manuscript. LM, $M L, X Z$ and $W L$ helped to designed the whole project and draft the manuscript. MS, FX, LY, WZ and ZL conducted cell culture and sample processing for sequencing. $\mathrm{XJ}$ conducted data analysis. All authors read and approved the final manuscript.

\section{Ethics approval and consent to participate} Not applicable.

\section{Consent for publication}

Not applicable.

\section{Competing interests}

The authors declare that they have no competing interests.

\section{Publisher's Note}

Springer Nature remains neutral with regard to jurisdictional claims in published maps and institutional affiliations.

\section{Author details}

${ }^{1}$ Institute of Veterinary Medicine, Jiangsu Academy of Agricultural Sciences, Key Laboratory of Veterinary Biological Engineering and Technology, Ministry of Agriculture, Nanjing 210014, China. ${ }^{2}$ School of Pharmacy, Linyi University, Linyi 276000, China. ${ }^{3}$ College of Animal Science, Guizhou University, Guiyang 550025, China. ${ }^{4}$ Key Lab of Food Quality and Safety of Jiangsu Province-State Key Laboratory Breeding Base, Nanjing 210014, China.

Received: 14 February 2019 Accepted: 1 May 2019

Published online: 17 May 2019

\section{References}

1. Li W, Mao L, Cheng S, Wang Q, Huang J, Deng J, Wang Z, Zhang W, Yang L, Hao F, et al. A novel parainfluenza virus type 3 (PIV3) identified from goat herds with respiratory diseases in eastern China. Vet Microbiol. 2014;174(1-2):100-6.

2. Yang L, Li W, Mao L, Hao F, Wang Z, Zhang W, Deng J, Jiang J. Analysis on the complete genome of a novel caprine parainfluenza virus 3. Infect Genet Evol. 2016:38:29-34

3. Li W, Hao F, Mao L, Wang Z, Zhou T, Deng J, Li J, Zhang W, Yang L, Lv Y, et al. Pathogenicity and horizontal transmission studies of caprine parainfluenza virus type 3 JS2013 strain in goats. Virus Res. 2016;223:80-7.

4. Mao L, Li W, Zhou T, Yang L, Hao F, Li J, Zhang W, Luo X, Jiang J. Development of a blocking ELISA for caprine parainfluenza virus type 3. J Virol Methods. 2017;250:59-65.

5. Li J, Li W, Mao L, Hao F, Yang L, Zhang W, Jiang J. Rapid detection of novel caprine parainfluenza virus type 3 (CPIV3) using a TaqMan-based RT-qPCR. J Virol Methods. 2016;236:126-31.

6. Mao L, Yang L, Li W, Liang P, Zhang S, Li J, Sun M, Zhang W, Wang L, Zhong C, et al. Epidemiological investigation and phylogenetic analysis of caprine parainfluenza virus type 3 in sheep of China. Transbound Emerg Dis. 2019. https://doi.org/10.1111/tbed.13149.

7. Zheng J, Sugrue RJ, Tang K. Mass spectrometry based proteomic studies on viruses and hosts--a review. Anal Chim Acta. 2011;702(2):149-59.

8. Han K, Zhao D, Liu Y, Liu Q, Huang X, Yang J, An F, Li Y. Quantitative proteomic analysis of duck ovarian follicles infected with duck Tembusu virus by label-free LC-MS. Front Microbiol. 2016;7:463.

9. Yang Y, Bu D, Zhao X, Sun P, Wang J, Zhou L. Proteomic analysis of cow, yak, buffalo, goat and camel milk whey proteins: quantitative differential expression patterns. J Proteome Res. 2013;12(4):1660-7.

10. Pandey A, Sahu AR, Wani SA, Saxena S, Kanchan S, Sah V, Rajak KK, Khanduri A, Sahoo AP, Tiwari AK, et al. Modulation of host miRNAs transcriptome in lung and spleen of Peste des Petits ruminants virus infected sheep and goats. Front Microbiol. 2017;8:1146.

11. Fernandez de Mera IG, Chaligiannis I, Hernandez-Jarguin A, Villar M, MateosHernandez L, Papa A, Sotiraki S, Ruiz-Fons F, Cabezas-Cruz A, Gortazar C, et al. Combination of RT-PCR and proteomics for the identification of CrimeanCongo hemorrhagic fever virus in ticks. Heliyon. 2017;3(7):e00353.

12. Hagglund S, Blodorn K, Naslund K, Vargmar K, Lind SB, Mi J, Arainga M, Riffault S, Taylor G, Pringle J, et al. Proteome analysis of bronchoalveolar lavage from calves infected with bovine respiratory syncytial virus-insights in pathogenesis and perspectives for new treatments. PLoS One. 2017; 12(10):e0186594

13. Sun $D$, Zhang $H$, Guo D, Sun A, Wang H. Shotgun proteomic analysis of plasma from dairy cattle suffering from footrot: characterization of potential disease-associated factors. PLoS One. 2013;8(2):e55973.

14. He Y, Li W, Liao G, Xie J. Mycobacterium tuberculosis-specific phagosome proteome and underlying signaling pathways. J Proteome Res. 2012;11(5):2635-43.

15. Zeng S, Zhang H, Ding Z, Luo R, An K, Liu L, Bi J, Chen H, Xiao S, Fang L. Proteome analysis of porcine epidemic diarrhea virus (PEDV)-infected Vero cells. Proteomics. 2015;15(11):1819-28.

16. Linde ME, Colquhoun DR, Ubaida Mohien C, Kole T, Aquino V, Cotter R, Edwards N, Hildreth JE, Graham DR. The conserved set of host proteins incorporated into HIV-1 virions suggests a common egress pathway in multiple cell types. J Proteome Res. 2013;12(5):2045-54.

17. Sun D, Shi H, Guo D, Chen J, Shi D, Zhu Q, Zhang X, Feng L. Analysis of protein expression changes of the Vero E6 cells infected with classic PEDV 
strain CV777 by using quantitative proteomic technique. J Virol Methods. 2015;218:27-39.

18. Cho YE, Singh TS, Lee HC, Moon PG, Lee JE, Lee MH, Choi EC, Chen YJ, Kim $\mathrm{SH}$, Baek MC. In-depth identification of pathways related to cisplatininduced hepatotoxicity through an integrative method based on an informatics-assisted label-free protein quantitation and microarray gene expression approach. Mol Cell Proteomics. 2012;11(1):M111 010884.

19. Zhang $X$, Zhou J, Wu Y, Zheng X, Ma G, Wang Z, Jin Y, He J, Yan Y. Differential proteome analysis of host cells infected with porcine circovirus type 2. J Proteome Res. 2009;8(11):5111-9.

20. Maxwell KL, Frappier L. Viral proteomics. Microbiol Mol Biol Rev. 2007;71(2): 398-411.

21. An K, Fang L, Luo R, Wang D, Xie L, Yang J, Chen H, Xiao S. Quantitative proteomic analysis reveals that transmissible gastroenteritis virus activates the JAK-STAT1 signaling pathway. J Proteome Res. 2014;13(12):5376-90.

22. Zhang LK, Chai F, Li HY, Xiao G, Guo L. Identification of host proteins involved in Japanese encephalitis virus infection by quantitative proteomics analysis. J Proteome Res. 2013;12(6):2666-78.

23. Braga ACS, Carneiro BM, Batista MN, Akinaga MM, Bittar C, Rahal P. Heat shock proteins HSPB8 and DNAJC5B have HCV antiviral activity. PLoS One. 2017;12(11):e0188467.

24. Rathore AP, Haystead T, Das PK, Merits A, Ng ML, Vasudevan SG Chikungunya virus nsP3 \& nsP4 interacts with HSP-90 to promote virus replication: HSP-90 inhibitors reduce CHIKV infection and inflammation in vivo. Antivir Res. 2014;103:7-16.

25. Zhong M, Zheng K, Chen M, Xiang Y, Jin F, Ma K, Qiu X, Wang Q, Peng T, Kitazato $\mathrm{K}$, et al. Heat-shock protein 90 promotes nuclear transport of herpes simplex virus 1 capsid protein by interacting with acetylated tubulin. PLoS One. 2014;9(6):e99425.

26. Patton JT, Chizhikov V, Taraporewala Z, Chen D. Virus replication. Methods Mol Med. 2000;34:33-66.

27. McLaughlin K, Carr VB, Iqbal M, Seago J, Lefevre EA, Robinson L, Prentice H, Charleston B. Hsp110-mediated enhancement of CD4+ T cell responses to the envelope glycoprotein of members of the family Flaviviridae in vitro does not occur in vivo. Clin Vaccine Immunol. 2011;18(2):311-7.

28. Hunter-Lavin C, Davies EL, Bacelar MM, Marshall MJ, Andrew SM, Williams $\mathrm{JH}$. Hsp70 release from peripheral blood mononuclear cells. Biochem Biophys Res Commun. 2004;324(2):511-7.

29. Yang Z, Zhuang L, Szatmary P, Wen L, Sun H, Lu Y, Xu Q, Chen X. Upregulation of heat shock proteins (HSPA12A, HSP90B1, HSPA4, HSPA5 and HSPA6) in tumour tissues is associated with poor outcomes from HBV-related early-stage hepatocellular carcinoma. Int J Med Sci. 2015;12(3):256-63.

30. Cheung RK, Dosch HM. The growth transformation of human B cells involves superinduction of hsp70 and hsp90. Virology. 1993;193(2):700-8.

31. Lefeuvre A, Contamin H, Decelle T, Fournier C, Lang J, Deubel V, Marianneau P. Host-cell interaction of attenuated and wild-type strains of yellow fever virus can be differentiated at early stages of hepatocyte infection. Microbes Infect. 2006;8(6):1530-8.

32. Liao WJ, Fan PS, Fu M, Fan XL, Liu YF. Increased expression of $70 \mathrm{kD}$ heat shock protein in cultured primary human keratinocytes induced by human papillomavirus 16 E6/E7 gene. Chin Med J. 2005;118(24):2058-62.

33. Mayer MP. Recruitment of Hsp70 chaperones: a crucial part of viral survival strategies. Rev Physiol Biochem Pharmacol. 2005;153:1-46.

34. Mansilla MJ, Costa C, Eixarch H, Tepavcevic V, Castillo M, Martin R, Lubetzki C, Aigrot MS, Montalban X, Espejo C. Hsp70 regulates immune response in experimental autoimmune encephalomyelitis. PLoS One. 2014;9(8):e105737.

35. Rusai K, Banki NF, Prokai A, Podracka L, Szebeni B, Tulassay T, Reusz GS, Sallay P, Kormendy R, Szabo AJ, et al. Heat shock protein polymorphism predisposes to urinary tract malformations and renal transplantation in children. Transplant Proc. 2010;42(6):2309-11.

36. Zulaziz N, Azhim A, Himeno N, Tanaka M, Satoh Y, Kinoshita M, Miyazaki H, Saitoh D, Shinomiya N, Morimoto Y. Photodynamic therapy mediates innate immune responses via fibroblast-macrophage interactions. Hum Cell. 2015;28(4):159-66.

37. Unwin RD, Griffiths JR, Whetton AD. Simultaneous analysis of relative protein expression levels across multiple samples using ITRAQ isobaric tags with 2D nano LC-MS/MS. Nat Protoc. 2010;5(9):1574-82.

38. Kanehisa M, Goto S, Sato Y, Furumichi M, Tanabe M. KEGG for integration and interpretation of large-scale molecular data sets. Nucleic Acids Res. 2012:40(Database issue):D109-14.

39. Reed $\amalg$, Muench $\mathrm{H}$. A simple method of estimation of fifty percent endpoint. Am J Epidemiol. 1938;27:493-7.

Ready to submit your research? Choose BMC and benefit from:

- fast, convenient online submission

- thorough peer review by experienced researchers in your field

- rapid publication on acceptance

- support for research data, including large and complex data types

- gold Open Access which fosters wider collaboration and increased citations

- maximum visibility for your research: over $100 \mathrm{M}$ website views per year

At BMC, research is always in progress.

Learn more biomedcentral.com/submissions 